\title{
The bone tissue compatibility of a new Ti35Nb2Ta3Zr alloy with a low Young's modulus
}

\author{
YONGYUAN GUO ${ }^{1}$, DESHENG CHEN ${ }^{1,2}$, MENGQI CHENG $^{1}$, WEIJIE LU ${ }^{3}$, \\ LIQIANG WANG $^{3}$ and XIANLONG ZHANG $^{1}$
}

\begin{abstract}
${ }^{1}$ Department of Orthopedics, The Sixth Affiliated People's Hospital, Medical School of Shanghai Jiao Tong University, Shanghai; ${ }^{2}$ Department of Orthopedics, The General Hospital of Ningxia Medical University, Yinchuan; ${ }^{3}$ State Key Laboratory of Metal Matrix Composites, Shanghai Jiao Tong University, Shanghai, P.R. China
\end{abstract}

Received November 7, 2012; Accepted December 24, 2012

DOI: $10.3892 /$ ijmm.2013.1249

\begin{abstract}
Titanium (Ti) alloys of the $\beta$-type are highly attractive metallic materials for biomedical applications due to their low elastic modulus, high corrosion resistance and notable biocompatibility. A new $\beta$-type Ti35Nb2Ta3Zr alloy with a low Young's modulus of approximately $48 \mathrm{GPa}$ was previously fabricated. In the present study, the biocompatibility of this alloy was evaluated. In an in vitro assay, the Ti35Nb2Ta3Zr alloy did not markedly affect the adhesion of MG63 osteoblast cells, but it increased their proliferation, alkaline phosphatase (ALP) activity, calcium deposition and mRNA expression of osteogenic genes (i.e., ALP, osteocalcin, osteopontin). In an in vivo study, no marked histological differences were observed between the new bone formed on the surface of $\mathrm{Ti} 35 \mathrm{Nb} 2 \mathrm{Ta} 3 \mathrm{Zr}$ and that formed on the surface of control Ti6Al4V rods placed in the medullary canal of rabbit femurs. Additionally, no significant differences were observed in the failure load of Ti35Nb2Ta3Zr and Ti6Al4V in pull-out tests. In conclusion, the Ti35Nb2Ta3Zr alloy with a lower elastic modulus closer to that of human bone has significant bone tissue compatibility equal to that of Ti6Al4V, which has been widely used in orthopedic applications.
\end{abstract}

\section{Introduction}

Pure titanium (CP-Ti; $\alpha$-type titanium alloy) and Ti6Al4V $(\alpha+\beta$-type titanium alloy), compared with other metallic

Correspondence to: Professor Xianlong Zhang, Department of Orthopedics, The Sixth Affiliated People's Hospital, Medical School of Shanghai Jiao Tong University, 600 Yishan Road, Shanghai 200233, P.R. China

E-mail: orthopedics2012@163.com

Dr Liqiang Wang, State Key Laboratory of Metal Matrix Composites, Shanghai Jiao Tong University, 800 Dongchuan Road, Shanghai 200244 , P.R. China

E-mail: titanium12@163.com

Key words: $\beta$-type titanium alloy, bone tissue compatibility, in vitro, in vivo biomaterials, have attracted considerable attention for biomedical applications due to their excellent specific corrosion resistance and high biocompatibility with bone (1). However, although the elastic modulus of the Ti6Al4V alloy $(110 \mathrm{GPa})$ is substantially lower than that of the Co-Cr-Mo alloy (230 GPa) and stainless steel (205 GPa), which are used as biomaterials, it is still much higher than that of human cortical bone (10-30 GPa) (2). A lower elastic modulus is important for minimizing the undesirable complication of stress shielding-bone resorption caused by unbalanced stress distribution between the bone and implant. In addition, vanadium has been previously found to be toxic to the human body $(3,4)$. Therefore, to resolve the drawbacks of the Ti6Al4V alloy, $\beta$-type Ti alloys are increasingly being considered for use in medical implants due to their lower elastic modulus and lack of toxic elements.

In particular, a review of 15 titanium alloys, including Ti6Al4V, CP-Ti, and $\beta$-type titanium alloys, showed that the Young's modulus of all $\beta$-type titanium alloys was lower than that of $\alpha$ or $\alpha+\beta$-type titanium alloys, and that the Ti35Nb5Ta7Zr alloy showed the lowest Young's modulus (55 GPa). With regard to toxicity, $\beta$-type Ti alloys consist of $\beta$-stabilizing elements such as $\mathrm{Nb}, \mathrm{Mn}, \mathrm{Sn}$, Ta and $\mathrm{Zr}$, which are considered safe for the human body $(5,6)$. Moreover, the biocompatibility of the $\beta$-type Ti alloy has been extensively investigated. Miura et al (7) reported that osteoblasts cultured on the surface of the TiNbSn alloy and on CP-Ti surface showed no significant differences in the relative growth ratio and relative absorbance ratio, indicating that the bone compatibility of the TiNbSn alloy is similar to that of CP-Ti.

A new $\beta$-type alloy composed of nontoxic elements, $\mathrm{Ti} 35 \mathrm{Nb} 2 \mathrm{Ta} 3 \mathrm{Zr}$, has been fabricated by vacuum consumable arc remelting. Our preliminary experiments focused on the microstructure and mechanical properties of $\mathrm{Ti} 35 \mathrm{Nb} 2 \mathrm{Ta} 3 \mathrm{Zr}$, and showed that the new alloy exhibited a considerably low Young's modulus (approximately $48 \mathrm{GPa}$ ) and a high ultimate tensile strength (approximately $880 \mathrm{MPa}$ ) after cold rolling $(8,9)$; therefore, it could be a suitable candidate for orthopedic applications. For clinical applications, biological compatibility must be evaluated in vitro and in vivo. Therefore, the present study evaluated the bone tissue compatibility of the new Ti35Nb2Ta3Zr alloy as a first step toward its use for biomedical applications. 


\section{Materials and methods}

Specimen preparation. The Ti35Nb2Ta3Zr alloy (wt \%) was prepared by arc melting a mixture of high-purity sponge $\mathrm{Ti}$, $\mathrm{Ti}-\mathrm{Nb}$ interalloy, and high-purity $\mathrm{Ta}$ and $\mathrm{Zr}$. The ingot was re-melted 3 times at 1,223 $\mathrm{K}$ for $1 \mathrm{~h}$ under vacuum to ensure compositional homogeneity and then forged into a quadrate cast with a width of $70 \mathrm{~mm}$, thickness of $30 \mathrm{~mm}$, and length of $100 \mathrm{~mm}$. Following solid solution at $1,053 \mathrm{~K}$ for $0.5 \mathrm{~h}$, the alloy was rolled to reduce its thickness by $99 \%$.

Pure Ti, Ti6Al4V and Ti35Nb2Ta3Zr were machined to disks with a diameter of $13 \mathrm{~mm}$ and a thickness of $1 \mathrm{~mm}$ to fit the 24-well plates. The surfaces of the disks were ground using a series of water-resistant emery papers with various degrees of coarseness up to 1,200 grit. All the disks were cleaned in an ultrasonic bath with ethanol and deionized (Milli-Q) water, followed by sterilization in an autoclave prior to cell culture.

Surface characterization. The surface topography was imaged using a field-emission scanning electron microscope (FESEM, FEI NOVA NanoSEM). The surface roughness (Ra) was determined using atomic force microscopy (AFM, Nanoscope 3; Bruker, Germany). Energy-dispersive X-ray detection (EDX, X-Max 80; Oxford Instruments, UK) was used to determine the elemental composition. The contact angle was measured using a video contact-angle measurement system.

Cell culture. MG63 cells (Cell Bank of the Chinese Science Academy, China) were cultured in Dulbecco's modified Eagle's medium (DMEM) supplemented with $10 \%(\mathrm{v} / \mathrm{v})$ fetal bovine serum (Gibco) and $1 \%$ penicillin/streptomycin at $37^{\circ} \mathrm{C}$ in an atmosphere of $5 \% \mathrm{CO}_{2}$ and $95 \%$ air. The cells were cultured in osteogenic media [the regular media described earlier, supplemented with $10 \mathrm{mM} \beta$-glycerophosphate, $0.2 \mathrm{mM}$ ascorbic acid, and $10^{-8} \mathrm{M}$ dexamethasone (Sigma)] to study cell differentiation. The culture medium was replaced every 2 or 3 days. The cells were passaged by lifting with trypsin/EDTA until they reached $80 \%$ confluence.

Cell adhesion. Osteoblasts were seeded on the samples at a density of $1 \times 10^{4}$ cells $/ \mathrm{cm}^{2}$. Following culture for $12 \mathrm{~h}$, the non-adherent cells were removed by rinsing with phosphatebuffered saline (PBS). The cells were fixed with 95\% alcohol and stained with 4',6'-diamidino-2-phenylindole (DAPI). The cells in 5 random fields were counted at low magnification under a fluorescence microscope (Leica DM400).

Cell viability. The Cell Counting Kit-8 (CCK-8; Dojindo, Japan) was used to determine the number of viable cells. In this assay, 2-(2-methoxy-4-nitrophenyl)-3-(4-nitrophenyl)5-(2,4-disulfophenyl)-2H-tetrazolium, monosodium salt (WST-8) is reduced by dehydrogenases in the cells to provide an orange-colored product (formazan) that is soluble in the tissue culture medium. The amount of the formazan dye generated by the dehydrogenases in the cells is directly proportional to the number of living cells. One milliliter of the cell suspension was seeded onto each specimen with a density of $2 \times 10^{4}$ cells $/ \mathrm{ml}$. At $1,4,8$ and 16 days after seeding, the samples were gently rinsed 3 times with PBS, and $20 \mu 1$ of prewarmed CCK-8 solution was added in $180 \mu \mathrm{l}$ of culture medium. After
$1 \mathrm{~h}$ of further incubation, $100 \mu \mathrm{l}$ of the working solution was transferred to a new 96-well culture plate for measurement of the absorbance using an ELISA reader at $450 \mathrm{~nm}$.

Cell morphology. MG63 cells were seeded on the samples for 1 and 4 days at a density of $1 \times 10^{4}$ cells/ $/ \mathrm{cm}^{2}$. At the prescribed time-points, the cells were fixed with $4 \%$ paraformaldehyde (Sigma) and washed with PBS. They were then permeabilized with $0.1 \%$ Triton X-100 and rinsed 3 times with PBS. Nonspecific binding sites were blocked with $1 \%$ BSA in PBS. Subsequently, the samples were incubated for $1 \mathrm{~h}$ with $200 \mu \mathrm{l}$ of TRITC-conjugated phalloidin (Molecular Probes, USA) in a humidified chamber at room temperature in the dark. Finally, cell nuclei were stained by incubation with $5 \mu \mathrm{g} / \mathrm{ml}$ DAPI (Dojindo) followed by 2 PBS rinses. The morphology of the cells was examined by confocal laser scanning microscopy (LSM-510; Carl Zeiss, Germany).

Alkaline phosphatase (ALP) activity. MG63 cells were seeded on the samples at a density of $1 \times 10^{4}$ cells $/ \mathrm{cm}^{2}$. The ALP activity was examined after the cells were cultured for 4,8 and 16 days by measuring the transformation of p-nitrophenylphosphate (pNPP) into p-nitrophenol (pNP). Following the selected incubation periods, the cells were rinsed 3 times with PBS and lysed in 0.1\% Triton X-100 (Sigma) by using standard freeze-thaw cycling. Fifty microliters of the sample were mixed with $50 \mu \mathrm{l}$ of freshly prepared pNPP substrate $(1 \mathrm{mg} / \mathrm{ml})$ and incubated at $37^{\circ} \mathrm{C}$ for $30 \mathrm{~min}$. The reaction was stopped by the addition of $50 \mu \mathrm{l}$ of $0.2 \mathrm{M} \mathrm{NaOH}$. The amount of pNP produced was quantified by measuring the absorbance at $405 \mathrm{~nm}$ in an ELISA reader. The total protein content was measured using a BCA protein assay kit and calculated with respect to a series of albumin (BSA) standards. Finally, the ALP activity was normalized to the total protein content.

Calcium deposition. Mineralization was detected and quantified by Alizarin Red S (ARS) staining at 8 and 16 days. Cells were seeded on the samples at a density of $1 \times 10^{4} \mathrm{cells} / \mathrm{cm}^{2}$. At the indicated time-points, the samples were washed 3 times in PBS and fixed in $4 \%$ paraformaldehyde for $30 \mathrm{~min}$. The cells were then rinsed with $\mathrm{ddH}_{2} \mathrm{O}$ and stained with ARS $(40 \mathrm{mM})$ for $20 \mathrm{~min}$ at room temperature. After the nonspecific staining was removed by rinsing with $\mathrm{ddH}_{2} \mathrm{O}$, the stain was desorbed with $10 \%$ cetylpyridinium chloride (Sigma). Finally, the dye was transferred to a 96-well plate and quantified using an ELISA reader at an absorbance of $590 \mathrm{~nm}$.

Gene expression analysis by real-time polymerase chain reaction (RT-PCR). MG63 cells were seeded on the samples at a density of $1 \times 10^{4}$ cells $/ \mathrm{cm}^{2}$ and cultured for 16 days. At the prescribed time-point, the adherent cells were lysed by TRIzol (Invitrogen) and the total RNA was isolated according to the TRIzol protocol. Subsequently, the total RNA was reverse-transcribed to cDNA by using the RevertAid ${ }^{\mathrm{TM}}$ First Strand cDNA Synthesis kit (Fermentas) following the manufacturer's instructions. Specific primers for the genes encoding osteoblast-related proteins, ALP, osteocalcin (OC), and osteopontin (OP), and the housekeeping gene GAPDH were synthesized commercially (Generay, Shanghai, China). The specific primers are listed in Table I. Quantitative RT-PCR 
Table I. Primer sequences for polymerase chain reaction.

\begin{tabular}{ll}
\hline Gene & \multicolumn{1}{c}{ Primer sequences $\left(5^{\prime}-3^{\prime}\right)$} \\
\hline ALP & F: ATCGCCTACCAGCTCATG \\
& R: GTTCAGCTCGTACTGCATGTC \\
OC & F: CTCACACTCCTCGCCCTATT \\
& R: GGTCAGCCAACTCGTCCAG \\
OP & F: ACCTCACACATGGAAAGCGA \\
& R: CTGTGGAATTCACGGCTGAC \\
GAPDH & F: TGACATCAAGAAGGTGGTGA \\
& R: TCCACCACCCTGTTGCTGTA \\
\hline
\end{tabular}

ALP, alkaline phosphatase; OC, osteocalcin; OP, osteopontin; F, forward; $\mathrm{R}$, reverse.

was then performed using SYBR ${ }^{\circledR}-$ Green Premix Ex Taq $^{\mathrm{TM}}$ II (Takara). Threshold cycle $(\mathrm{Ct})$ values were obtained and the amplification was determined. The GAPDH gene was used as a reference control gene to normalize the expression values of the target genes. The results are reported as the relative gene expression calculated using the $2^{-\Delta \Delta \mathrm{Ct}}$ method.

Animal experiment. Twenty-four adult male New Zealand white rabbits weighing 3.0-3.5 kg were used for the implantation study. This animal experiment was approved by the Animal Care Committee of Shanghai Sixth Hospital. The animals were anesthetized with pentobarbital $(25 \mathrm{mg} / \mathrm{kg})$ by intravenous injection, and were administered cefazolin sodium (20 $\mathrm{mg} / \mathrm{kg}$ ) by intravenous injection prior to surgery. The distal medullary canal of the femur was used as the implantation site. Prior to the surgical procedure, the area surrounding the incision site was shaved and the skin was sterilized using iodophor disinfectant. A longitudinal incision was performed medially at the patella, and a $2.0-\mathrm{mm}$ drill bit was used to open the medullary canal through the intercondylar notch of the distal femur. The distal medullary canal was then gently reamed through a series of increasing drill bits $(3,4$ and $4.5 \mathrm{~mm}$ ). After the medullary canal was rinsed with normal saline, the implants were implanted into the medullary canal until the distal portion of the implant was at the same level as the entry hole. The implants were inserted into both femurs of each rabbit; the left femurs were used for the push-out test and the right femurs were used for the histological study. All rabbits were allowed to move freely using the operated limbs without any limitation after the operation, and the rabbits were observed daily for activity and weight-bearing on the operated limbs. The new bone formed was double labeled by tetracycline $(30 \mathrm{mg} / \mathrm{kg})$ and calcein $(5 \mathrm{mg} / \mathrm{kg})$ (Sigma), which were intraperitoneally injected 14 and 3 days, respectively, before the animals were sacrificed. The animals were sacrificed by an overdose of intravenous pentobarbital sodium 4, 8 and 12 weeks following rod implantation, with 4 animals in each group.

Radiographic evaluation. X-ray radiography was performed after the rabbits were sacrificed at 12 weeks to evaluate the osseointegration between the implants and surrounding bone tissue.

Pull-out test. The pull-out test was performed within $12 \mathrm{~h}$ after the animals were sacrificed. The femur implanted with the rod was excised, and the protruding portion of the implant was exposed for attachment to the testing machine (Instron 5569; Instron, USA). The maximum pull-out force was recorded at 4,8 and 12 weeks to indicate the quality of the attachment to the bone tissue.

Histological evaluation. After the animals were sacrificed at the prescribed time-points, the bone with the implant was fixed in acetone for 7 days, dehydrated in ascending grades of ethanol for 3 days each, and embedded in methyl methacrylate without decalcification. Sections $(150 \mu \mathrm{m})$ were cut from each sample using a bone saw (Leica SP1600) with the blade placed perpendicular to the long axis of the implant at 3 levels (proximal, middle and distal) of the femur (Fig. 1A). Subsequently, the sections were mounted on plastic slides and manually ground to a thickness of 50-100 $\mu \mathrm{m}$. Finally, the specimens were stained with $1 \%$ methylene blue. The stained sections were observed using a Leica microscope (Leica DM400), and the fluorochrome markers were evaluated using a fluorescent microscope (Leica DMI6000B). The surface bone apposition ratio [BAR (\%)] and the new bone area $\left[\mathrm{NBA}\left(\mathrm{mm}^{2}\right)\right]$ surrounding the implant were measured to evaluate the osseointegration. The circumference of the implant was recorded to calculate the percentage of the surface that was in direct contact with the bone in each section, and the BAR was defined as the percentage of the implant surface in direct contact with the bone. The area of the new bone tissue was measured in a circumferential area within $0.25 \mathrm{~mm}$ from the rod surface (Fig. 1B), and the NBA was determined by observing the methylene blue staining and labeling with tetracycline and calcein.

Statistical analysis. Statistical analyses were conducted using SPSS 16.0. The data were obtained from 3 independent experiments and expressed as the means \pm standard deviation. Differences among groups for the in vitro experiments were analyzed by one-way analysis (ANOVA). Two-way factorial ANOVA and Bonferroni post-hoc tests were used for the in vivo experiments. A $\mathrm{P}$-value of $<0.05$ was considered to indicate statistically significant differences.

\section{Results}

Surface characterization. The SEM micrographs of Ti, Ti6A14V, and Ti35Nb2Ta3Zr are presented in Fig. 2. The element composition measured by EDX was as follows: Ti, 59.55\%; Nb, 35.44\%; Ta, 2.14\%; and $\mathrm{Zr}, 2.86 \%$. The EDX results show that the Ti35Nb2Ta3Zr alloy consisted of $\mathrm{Ti}, \mathrm{Nb}$, Ta and $\mathrm{Zr}$; $\mathrm{Al}$ and $\mathrm{V}$ were not observed. The Ra of the Ti, Ti6A14V and Ti35Nb2Ta3Zr samples determined by AFM (Fig. 2) is summarized in Table II. The Ra of Ti35Nb2Ta3Zr was the highest among the 3 samples. The surface wettability measured as the water contact angle is also listed in Table II; the surface of Ti35Nb2Ta3Zr was found to be more hydrophilic than that of Ti and Ti6Al4V. 
A

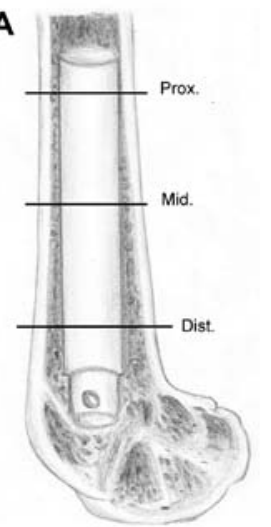

B

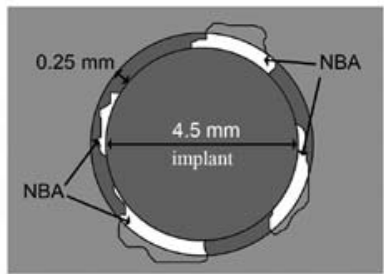

Figure 1. (A) Schematic drawing of the distal femur of a rabbit. The implant was inserted into the medullary canal. Lines Prox, Mid and Dist indicate the proximal, middle and distal section levels, respectively, for histological evaluation. (B) Schematic representation of the new bone area (NBA; white area). The NBA was defined as the white area within the ring around the implant.
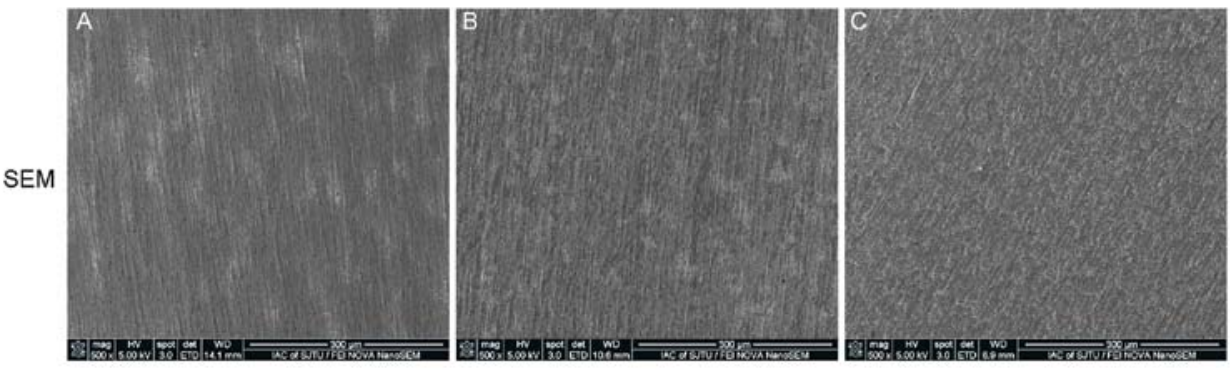

A

AFM

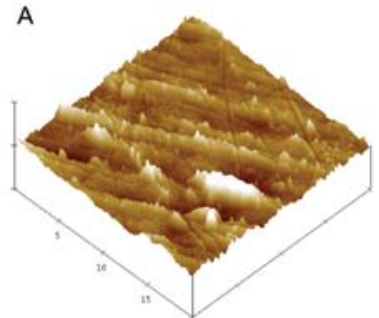

B
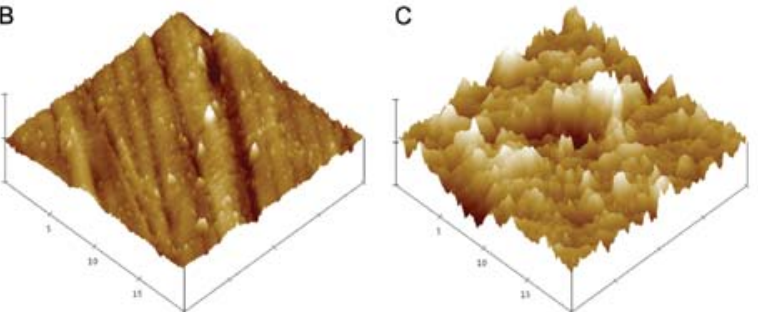

Figure 2. Representative SEM and AFM images of the surface (A) Ti, (B) Ti6A14V and (C) Ti35Nb2Ta3Zr.

Table II. Comparison among Ti, Ti6Al4V and Ti35Nb2Ta3Zr in terms of surface properties.

\begin{tabular}{lcc}
\hline & $\mathrm{Ra}(\mathrm{nm})$ & Contact angle $\left({ }^{\circ}\right)$ \\
\hline $\mathrm{Ti}$ & $31.933 \pm 3.61$ & $39.8 \pm 2.6$ \\
Ti6Al4V & $24.235 \pm 4.28$ & $41.3 \pm 1.9$ \\
Ti35Nb2Ta3Zr & $49.667 \pm 8.02$ & $32.1 \pm 2.0$ \\
\hline
\end{tabular}

Cell adhesion and viability. The fluorescence micrographs of cells stained with DAPI indicate cell attachment (Figs. 3 and 4). No significant differences were observed among the substrates after $12 \mathrm{~h}$ of culture. Fig. 4 shows the viability of MG63 cells as measured by CCK8 following culture for 1, 4, 8 and 16 days on the 3 different alloys. The cell viability increased with time on all substrates. On Day 1, the cell proliferation was higher on Ti and Ti35Nb2Ta3Zr than on Ti6Al4V but it did not differ between $\mathrm{Ti}$ and Ti35Nb2Ta3Zr. From Day 4, cells cultured on
Ti35Nb2Ta3Zr proliferated more rapidly than those cultured on $\mathrm{Ti}$, and significant differences were observed between $\mathrm{Ti}$ and Ti35Nb2Ta3Zr on Days 4, 8 and 16.

Cell morphology. Fig. 5 shows the morphology of osteoblasts with dual staining of actin filaments and nuclei following culture on the surfaces of the Ti, Ti6Al4V and Ti35Nb2Ta3Zr samples. On Day 1, round or fusiform cells were observed on the samples, and several pseudopodia of the osteoblasts were clearly observed on the surface of Ti35Nb2Ta3Zr. On Day 4, the osteoblasts had spread well and showed a polygonal shape, and actin filaments were clearly observed on all the samples.

ALP activity and calcium deposition. Fig. 4 shows the ALP activity of osteoblasts cultured on Ti, Ti6A14V and Ti35Nb2Ta3Zr samples on 4, 8 and 16 days. The findings for ALP activity were similar to those for cell viability. Among the 3 samples, Ti35Nb2Ta3Zr exhibited the highest ALP activity at all time-points $(\mathrm{P}<0.05)$. The Alizarin Red assay was used to determine the extent of calcium mineralization. Fig. 4 shows 

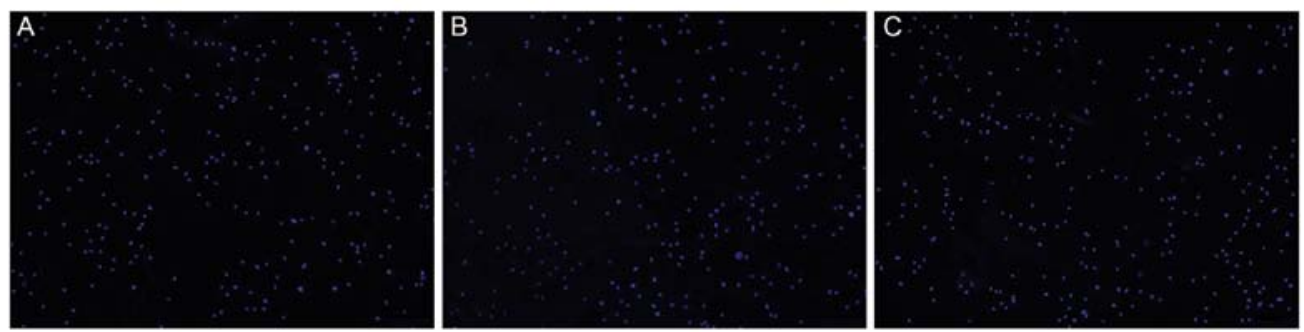

Figure 3. Fluorescence micrographs of osteoblasts (nuclei in blue) incubated on (A) Ti, (B) Ti6Al4V and (C) Ti35Nb2Ta3Zr after $12 \mathrm{~h}$ of culture.
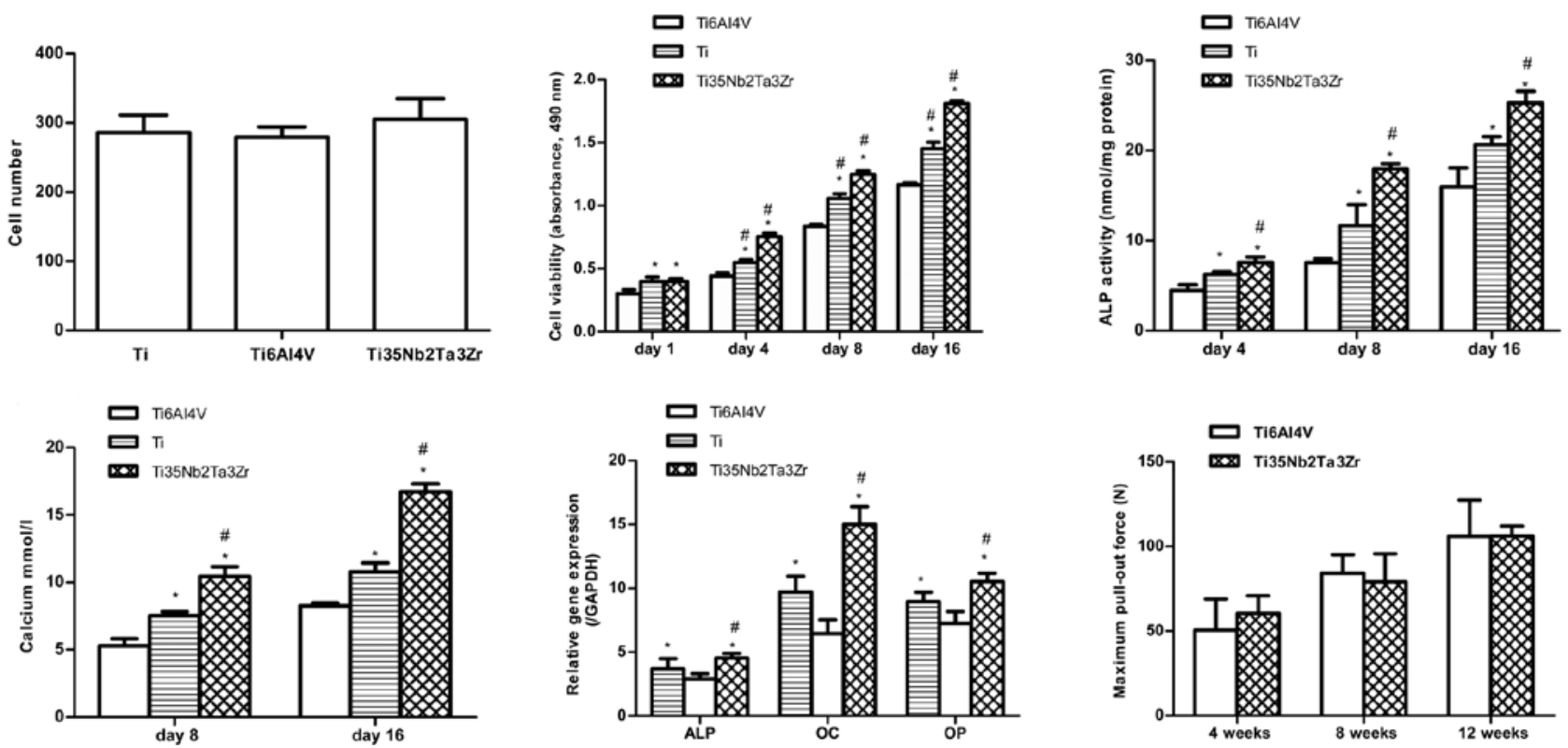

Figure 4. Osteoblast adhesion measured by cell counting at $12 \mathrm{~h}$, cell viability of MG63 cells after $1,4,8$ or 16 days of culture, ALP activity (normalized to total protein amounts) at 4, 8 and 16 days, calcium deposition after culture for 8 and 16 days and osteogenic mRNA expression (ALP, OC and OP) after culture for 16 days on Ti, Ti6A14V and Ti35Nb2Ta3Zr surfaces. The failure-load values of Ti6A14V and Ti35Nb2Ta3Zr alloys at 4, 8 and 12 weeks following implantation measured by the pull-out test. Data are shown as the means \pm SD. ${ }^{~} \mathrm{P}<0.05$ compared with Ti6Al4V; ${ }^{\#} \mathrm{P}<0.05$ compared with Ti. ALP, alkaline phosphatase; OC, osteocalcin; OP, osteopontin.
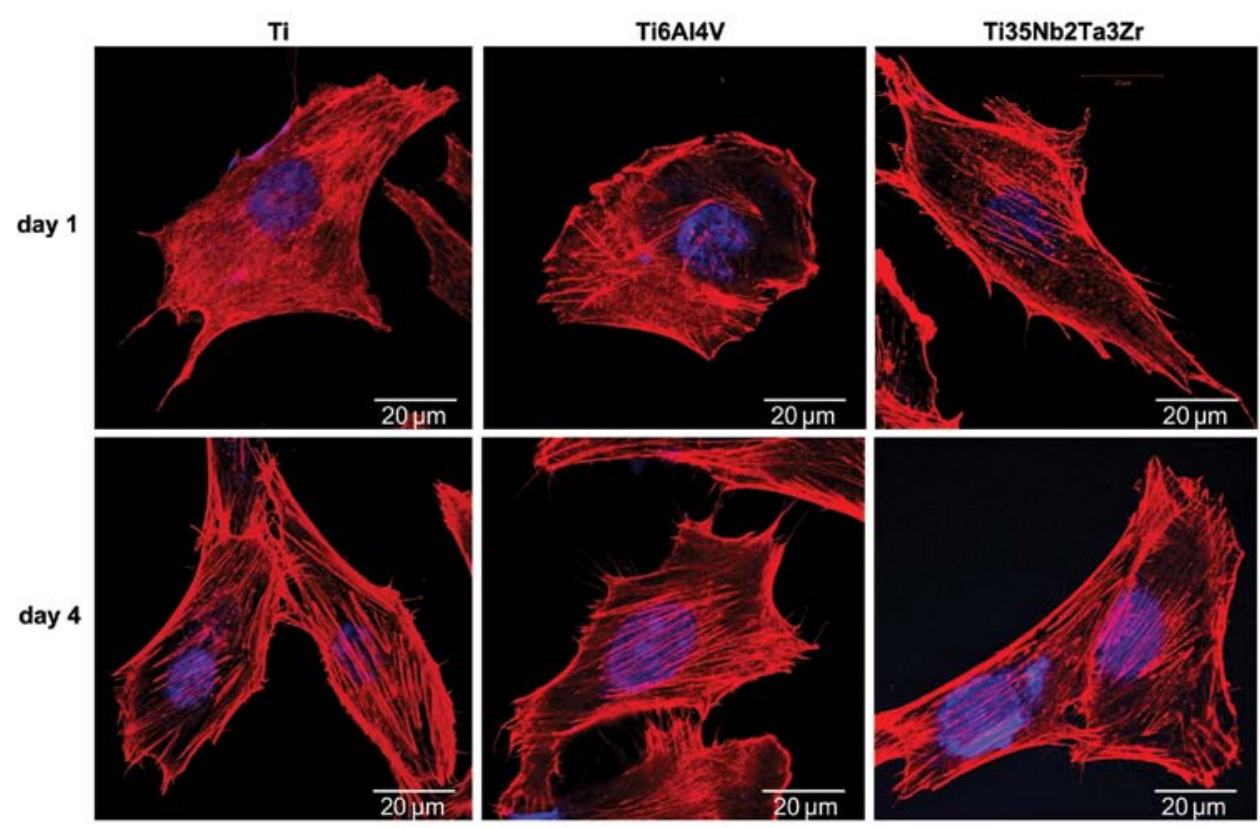

Figure 5. Fluorescence microscopy images of cells double stained with phalloidin for actin filaments (red) and DAPI for nuclei (blue) after 1 and 4 days of incubation on Ti, Ti6A14V and Ti35Nb2Ta3Zr samples. 


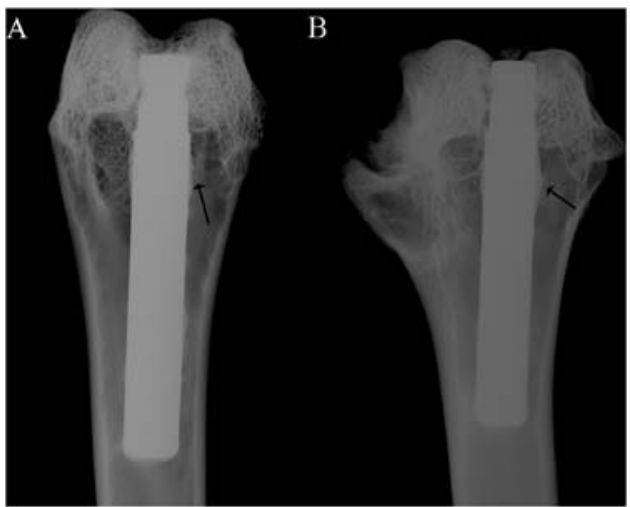

Figure 6. Typical radiographs of Ti6A14V and Ti35Nb2Ta3Zr alloys at 12 weeks after rod implantation. The new bone formed around the rod is indicated by arrows. (A) Ti6A14V and (B) Ti35Nb2Ta3Zr.

A
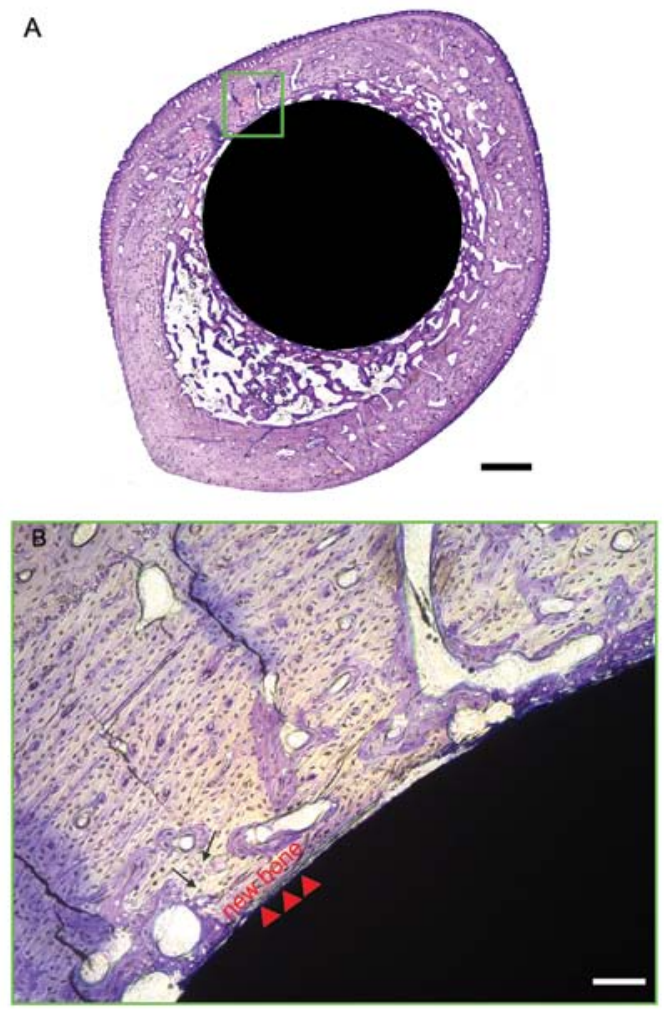

Figure 7. Histological analysis in the middle section stained with methylene blue (Ti35Nb2Ta3Zr alloy) 12 weeks after implantation. (A) Integral image around the rod observed by light microscopy. Bar, $1.0 \mathrm{~mm}$. (B) Magnification of the square area in (A) observed in fluorescent light micrographs. Bar, $100 \mathrm{~m}$ The newly formed bone directly contacted the rod surface (triangles). The arrows indicate newly formed osteocytes.

that the amount of calcium on all 3 different samples increased in a time-dependent manner, and the Ti35Nb2Ta3Zr surfaces, compared to $\mathrm{Ti}$ and $\mathrm{Ti6A14V}$, had significantly high calcium levels after 8 and 16 days of culture $(\mathrm{P}<0.05)$.

Real-time polymerase chain reaction analysis. The gene expression of MG63 cells grown on Ti, Ti6Al4V and Ti35Nb2Ta3Zr surfaces for 16 days was analyzed using RT-PCR (Fig. 4). Significantly higher mRNA levels of ALP, OC and OP were observed on the Ti35Nb2Ta3Zr surfaces on Day 16 than on
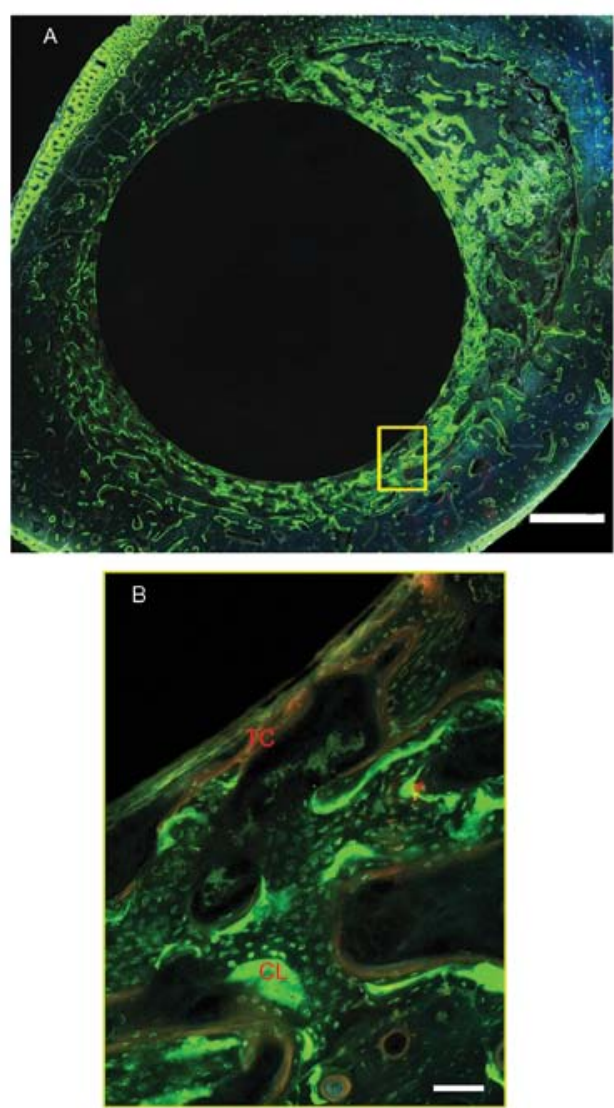

Figure 8. Representative images of bone labeling with tetracycline and calcein (Ti35Nb2Ta3Zr alloy) 8 weeks after implantation. (A) Integral image around the rod observed by fluorescent microscopy. Bar, $1.0 \mathrm{~mm}$. (B) Magnification of the square area in (A). Bar, $100 \mathrm{~m}$. New bone was marked with double yellow-green lines labeled with tetracycline (TC, yellow line) and calcein (CL, green line)

the Ti and Ti6Al4V surfaces $(\mathrm{P}<0.05)$, which indicates that the osteoblast differentiation was enhanced on $\mathrm{Ti} 35 \mathrm{Nb} 2 \mathrm{Ta} 3 \mathrm{Zr}$ surfaces compared with Ti and Ti6Al4V surfaces.

Radiographic evaluation. Fig. 6 shows typical radiographs of rabbit femurs 12 weeks following implantation with Ti6Al4V and Ti35Nb2Ta3Zr. The implants were located in the medullary canal, and no fractures were observed in the operated bone. New bone tissue was observed around the implants as indicated by the arrow in Fig. 6. No significant differences were observed among the radiographs for the different conditions.

Pull-out test. Fig. 4 shows the failure loads. The failure-load values gradually increased with time in both groups. However, there were no significant differences between the 2 alloys at any time.

Histological evaluation. Figs. 7 and 8 show representative histological images of the middle section of the Ti35Nb2Ta3Zr alloy at 12 weeks after implantation. Newly formed bone tissue was clearly observed around the surface of both the alloys. The dynamic process of new bone formation was observed by light microscopy and fluorescence microscopy (Fig. 8). As shown in Fig. 7, good contact was observed between the bone tissue and the Ti35Nb2Ta3Zr alloy. Under fluorescence microscopy, a double line of tetracycline and calcein was clearly observed, 

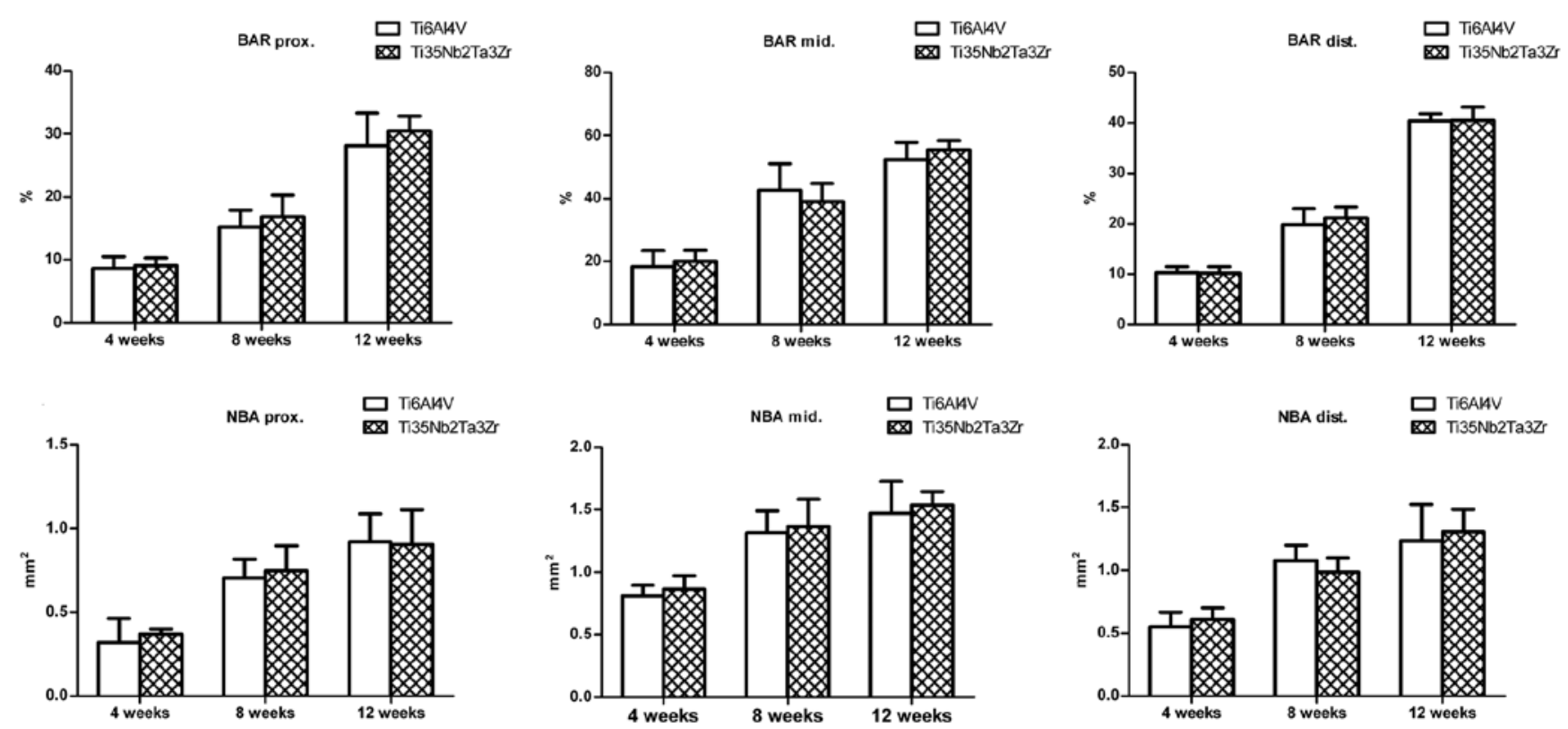

Figure 9. The surface bone apposition ratio [BAR (\%)] and NBA $\left(\mathrm{mm}^{2}\right)$ of Ti6Al4V and Ti35Nb2Ta3Zr alloys in the proximal, middle, and distal sections at 4,8 and 12 weeks. Data are shown as the means \pm SD.

indicating new bone formation. The formation of osteocytes (indicated by the arrows in Fig. 7) in the lamellar bone matrix was irregular, indicating that the bone tissue grew well on the surface of the alloys. The BAR and NBA at the surface of the Ti6A14V and Ti35Nb2Ta3Zr alloys gradually increased in the 3 sections of the femur. The BAR and NBA did not differ between the 2 groups in all sections of the femur at 4,8 and 12 weeks (Fig. 9).

\section{Discussion}

In the present study, the in vitro and in vivo biocompatibility of a $\beta$-type Ti35Nb2Ta3Zr alloy with a low elastic modulus of approximately $48 \mathrm{GPa}$ was evaluated.

In vitro biological properties. A direct-contact culture test was performed to assess the in vitro biocompatibility of Ti35Nb2Ta3Zr (10-13). Ti6Al4V and Ti were used as controls as they are known to be biocompatible. The proliferation of MG63 cells was higher on Ti35Nb2Ta3Zr than on Ti6A14V and Ti after culture for 4 days and remained high until Day 16. The dual staining of the actin filaments and nuclei of osteoblasts indicated that the cells had spread well on the 3 samples. Significant increases in the ALP activity and calcium deposition were observed at all time-points, consistent with the mRNA expression of the genes encoding the osteogenic proteins ALP, OC and OP.

Roughness and hydrophilicity are key factors in the response of cells to biomaterials. Rough, hydrophilic surfaces on Ti implants may increase the viability, ALP activity, and calcium deposition of osteoblasts in vitro (14-17). The molecular mechanisms responsible for the enhancement of osteogenic properties by surface topography have been evaluated in several studies. Zhuang et al (18) demonstrated that cells cultured on smooth surfaces treated with PD98095 (an ERK1/2 inhibitor) or rough SLA surfaces (sand-blasted acid-etched surfaces) without PD98095 treatment showed reduced extracellular signal-regulated kinase 1/2 (ERK1/2) phosphorylation and increased expression levels of osteogenic genes (i.e., Runx2, OSX, OPN and OCN). Thus, the effect of surface roughness on osteoblastic differentiation may be mediated through the inhibition of the ERK1/2 pathway, which is consistent with the findings of other studies $(19,20)$. Olivares-Navarrete et al (21) reported that the mRNA level of non-canonical pathway ligands, receptors, and intracellular signaling molecules was higher in cells cultured on SLA surfaces than in those cultured on smooth surfaces. In particular, increased ALP activity and osteocalcin production were observed after osteoblasts were treated with Wnt5a (a non-canonical pathway activator), suggesting that the noncanonical pathway was involved in the differentiation of osteoblasts on microstructured titanium surfaces. Similarly, Vlacic-Zischke et al (22) showed, using a whole-genome analysis, that the TGF- $\beta$ /BMP signaling pathway members BMP2, BMP6 and ACVR1 were upregulated in osteoblasts cultured on SLA and modSLA (hydrophilic SLA). The expression of miRNAs has also been investigated in relation to the modulation of osteogenic gene expression by SLA and modSLA surfaces. Target predictions for the differentially regulated miRNAs indicated that 35 and 10 miRNAs were downregulated and upregulated, respectively, on modSLA surfaces, and 32 and 9 miRNAs were downregulated and upregulated, respectively, on SLA surfaces. Additionally, several genes involved in the TGF- $\beta / \mathrm{BMP}$ and non-canonical Wnt $/ \mathrm{Ca}^{2+}$ pathways were identified as potential targets for the miRNAs during differentiation on modSLA and SLA surfaces. These mechanisms may also be involved in the enhanced proliferation and differentiation of osteoblasts that we observed on Ti35Nb2Ta3Zr surfaces, which, as described above, had rougher and more hydrophilic surfaces.

Tantalum and zirconium may have also contributed to the observed effects on osteoblast cells, since the positive effects 
of $\mathrm{Ta}$ and $\mathrm{Zr}$ on cell attachment, proliferation, and differentiation have been well documented (23-28). Stiehler et al (23) reported that mesenchymal stem cells cultured on Ta surfaces had a significantly increased mean cellular area and cellspecific ALP activity compared with those cultured on Ti and chromium surfaces. Additionally, Sista et al (26) showed that the adhesion, proliferation, and differentiation of MC3T3-E1 osteoblast cells were better on TiZr than on TiNb or Ti. A key factor for this difference was the presence of $\mathrm{Zr}$ in the TiZr alloy (26). A microRNA microarray analysis showed that NOG, SHOX, IGF1, BMP1 and FGFR1 are differentially regulated in osteoblasts exposed to zirconium (29). In the present study, Ta and $\mathrm{Zr}$ were confirmed to be present on the surface of Ti35Nb2Ta3Zr by EDX. Therefore, it is plausible that the presence of surface $\mathrm{Ta}$ and $\mathrm{Zr}$ may have contributed to the enhanced osteoblast function observed on Ti35Nb2Ta3Zr.

In vivo biomechanical and biological properties. In an in vivo study, intramedullary rods were inserted into rabbit femurs, and the bone compatibility of the Ti35Nb2Ta3Zr alloy was assessed in comparison to Ti6 Al4V, which is considered bioinert material and has been widely used in medical fields. The failure load gradually increased with time following implantation in both groups, but there were no significant differences between the failure loads of the Ti6Al4V and Ti35Nb2Ta3Zr alloys at any time-point. These results are in agreement with those of previous studies. Miura et al (7) evaluated the pull-out strength of Ti6Al4V and TiNbSn alloys at 3, 6 and 12 weeks following implantation and reported that the failure loads of the 2 alloys increased with time, with no differences observed between the alloys.

The methylene blue staining and double labeling of tetracycline and calcein were used to evaluate new bone formation at the bone-implant interface. The BAR and NBA of the Ti6Al4V and $\mathrm{Ti} 35 \mathrm{Nb} 2 \mathrm{Ta} 3 \mathrm{Zr}$ alloys gradually increased with time, and the values did not differ between the 2 alloys. These results are similar to those of previous studies. Miura et al (7) reported that the BAR and NBA of Ti6Al4V and TiNbSn beneath cortical bone increased with time, but the NBA of TiNbSn rapidly increased up to 6 weeks and reached a peak. Lin et al (30) evaluated Ti6Al4V and Ti7.5Mo alloys and obtained similar results. However, the NBA of Ti6Al4V surrounded by cancellous bone decreased with time after a peak at 12 weeks, and the NBA of Ti7.5Mo continually increased after 12 weeks. No peak was observed in our study. Although there was no significant difference in the BAR and NBA between Ti6Al4V and Ti35Nb2Ta3Zr, the values of BAR and NBA were higher for Ti35 Nb2Ta3Zr, indicating that the in vivo biocompatibility of $\mathrm{Ti} 35 \mathrm{Nb} 2 \mathrm{Ta} 3 \mathrm{Zr}$ is equal to that of Ti6A14V, which has been widely used in biomedical fields. The lesser stiffness of Ti35Nb2Ta3Zr may facilitate new bone formation.

In conclusion, the in vitro assay showed that the adhesion, proliferation, and differentiation of osteoblasts were better on Ti35Nb2Ta3Zr than on Ti and Ti6Al4V. The in vivo study showed that the extent of new bone formation around the Ti35Nb2Ta3Zr implants was equal to that around the Ti6A14V implants. In summary, the Ti35Nb2Ta3Zr alloy with a lower elastic modulus has notable bone tissue compatibility in vitro and in vivo, and may therefore be useful biomedical material in the future.

\section{Acknowledgements}

This study was supported by the National Natural Science Foundation of China (grant no. 81171688), the Interdisciplinary (Engineering-Medical) Research Fund of Shanghai Jiao Tong University (grant no. YG2011MS30), and the Shanghai Municipal Health Bureau Science Fund for Young Scholars (grant no. 2010QJ036A).

\section{References}

1. Rack H and Qazi J: Titanium alloys for biomedical applications. Mater Sci Eng C 26: 1269-1277, 2006.

2. Snyder SM and Schneider E: Estimation of mechanical properties of cortical bone by computed tomography. J Orthop Res 9: 422-431, 1991.

3. Rae T: The toxicity of metals used in orthopaedic prostheses. An experimental study using cultured human synovial fibroblasts. J Bone Joint Surg Br 63-B: 435-440, 1981.

4. Hallab NJ, Vermes C, Messina C, Roebuck KA, Glant TT and Jacobs JJ: Concentration- and composition-dependent effects of metal ions on human MG-63 osteoblasts. J Biomed Mater Res 60: 420-433, 2002.

5. Guillemot F: Recent advances in the design of titanium alloys for orthopedic applications. Expert Rev Med Devices 2: 741-748, 2005.

6. Long $\mathrm{M}$ and Rack HJ: Titanium alloys in total joint replacement a materials science perspective. Biomaterials 19: 1621-1639, 1998.

7. Miura K, Yamada N, Hanada S, Jung TK and Itoi E: The bone tissue compatibility of a new Ti-Nb-Sn alloy with a low Young's modulus. Acta Biomater 7: 2320-2326, 2011.

8. Wang LQ, Lu WJ, Qin JN, Zhang F and Zhang D: Change in microstructures and mechanical properties of biomedical Ti-Nb-Ta-Zr system alloy through cross-rolling. Mater Trans 49: 1791-1795, 2008.

9. Wang LQ, Lu WJ, Qin JN, Zhang F and Zhang D: Microstructure and mechanical properties of cold-rolled TiNbTaZr biomedical beta titanium alloy. Mater Sci Eng A Struct Mater 490: 421-426, 2008.

10. Zhu L, Wang H, Xu J, Lin J and Wang X: Effects of nacre-coated titanium surfaces on cell proliferation and osteocalcin expression in MG-63 osteoblast-like cells. Afr J Biotechnol 10: 15387-15393, 2011.

11. Lee MH, Kang JH and Lee SW: The significance of differential expression of genes and proteins in human primary cells caused by microgrooved biomaterial substrata. Biomaterials 33 : 3216-3234, 2012.

12. Hu Y, Cai K, Luo Z, et al: Regulation of the differentiation of mesenchymal stem cells in vitro and osteogenesis in vivo by microenvironmental modification of titanium alloy surfaces. Biomaterials 33: 3515-3528, 2012.

13. Schliephake H, Boetel C, Foerster A, Schwenzer B, Reichert J and Scharnweber D: Effect of oligonucleotide mediated immobilization of bone morphogenic proteins on titanium surfaces. Biomaterials 33: 1315-1322, 2012.

14. Qu Z, Rausch-Fan X, Wieland M, Matejka M and Schedle A: The initial attachment and subsequent behavior regulation of osteoblasts by dental implant surface modification. J Biomed Mater Res A 82: 658-668, 2007.

15. Rausch-fan X, Qu Z, Wieland M, Matejka M and Schedle A: Differentiation and cytokine synthesis of human alveolar osteoblasts compared to osteoblast-like cells (MG63) in response to titanium surfaces. Dent Mater 24: 102-110, 2008.

16. Zhao G, Raines A, Wieland M, Schwartz Z and Boyan B: Requirement for both micron-and submicron scale structure for synergistic responses of osteoblasts to substrate surface energy and topography. Biomaterials 28: 2821-2829, 2007.

17. Padial-Molina M, Galindo-Moreno P, Fernandez-Barbero JE, et al: Role of wettability and nanoroughness on interactions between osteoblast and modified silicon surfaces. Acta Biomater 7: 771-778, 2011.

18. Zhuang LF, Jiang HH, Qiao SC, et al: The roles of extracellular signal-regulated kinase $1 / 2$ pathway in regulating osteogenic differentiation of murine preosteoblasts MC3T3-E1 cells on roughened titanium surfaces. J Biomed Mater Res A 100: 125-133, 2012 . 
19. Higuchi C, Myoui A, Hashimoto N, et al: Continuous inhibition of MAPK signaling promotes the early osteoblastic differentiation and mineralization of the extracellular matrix. J Bone Miner Res 17: 1785-1794, 2002.

20. Kono S, Oshima Y, Hoshi K, et al: Erk pathways negatively regulate matrix mineralization. Bone 40: 68-74, 2007.

21. Olivares-Navarrete R, Hyzy SL, Hutton DL, et al: Role of non-canonical Wnt signaling in osteoblast maturation on microstructured titanium surfaces. Acta Biomater 7: 2740$2750,2011$.

22. Vlacic-Zischke J,Hamlet SM, Frus T, Tonetti MS and Ivanovski S: The influence of surface microroughness and hydrophilicity of titanium on the up-regulation of TGF $\beta /$ BMP signalling in osteoblasts. Biomaterials 32: 665-671, 2011.

23. Stiehler M, Lind M, Mygind T, et al: Morphology, proliferation, and osteogenic differentiation of mesenchymal stem cells cultured on titanium, tantalum, and chromium surfaces. J Biomed Mater Res A 86: 448-458, 2008.

24. Balla VK, Bodhak S, Bose S and Bandyopadhyay A: Porous tantalum structures for bone implants: fabrication, mechanical and in vitro biological properties. Acta Biomater 6: 3349-3359, 2010.
25. Balla VK, Banerjee S, Bose S and Bandyopadhyay A: Direct laser processing of a tantalum coating on titanium for bone replacement structures. Acta Biomater 6: 2329-2334, 2010.

26. Sista S, Wen C, Hodgson PD and Pande G: The influence of surface energy of titanium-zirconium alloy on osteoblast cell functions in vitro. J Biomed Mater Res A 97: 27-36, 2011.

27. Hempel U, Hefti T, Kalbacova M, Wolf-Brandstetter C, Dieter P and Schlottig F: Response of osteoblast-like SAOS-2 cells to zirconia ceramics with different surface topographies. Clin Oral Implants Res 21: 174-181, 2010.

28. Ramaswamy Y, Wu C, Van Hummel A, Combes V, Grau G and Zreiqat $\mathrm{H}$ : The responses of osteoblasts, osteoclasts and endothelial cells to zirconium modified calcium-silicate-based ceramic. Biomaterials 29: 4392-4402, 2008.

29. Palmieri A, Pezzetti F, Brunelli G, et al: Zirconium oxide regulates RNA interfering of osteoblast-like cells. J Mater Sci Mater Med 19: 2471-2476, 2008.

30. Lin DJ, Chuang CC, Chern Lin JH, Lee JW, Ju CP and Yin HS: Bone formation at the surface of low modulus Ti-7.5Mo implants in rabbit femur. Biomaterials 28: 2582-2589, 2007. 